Evidence-based

Speech-Language Pathology

Fonoaudiologia Baseada

em Evidências

Liliane Aparecida Fagundes Silva ${ }^{1}$

Maria Inês Vieira Couto ${ }^{1}$

Carla Gentile Matas ${ }^{1}$

Ana Claudia Martinho de Carvalho'

Keywords

Electrophysiology

Cochlear implantation

Child

Neuronal plasticity

Audiology

Descritores

Eletrofisiologia

Implante coclear

Criança

Plasticidade neuronal

Audiologia

Correspondence address:

Ana Claudia Martinho de Carvalho

Rua Cipotânea, 51, Cidade Universitária,

São Paulo (SP), Brasil, CEP: 05360-160.

E-mail: liliane.fagundes@usp.br

Received: 05/20/2013

Accepted: 09/06/2013

\section{Long latency auditory evoked potentials in children with cochlear implants: systematic review}

\author{
Potenciais evocados auditivos de longa latência em \\ crianças com implante coclear: revisão sistemática
}

\begin{abstract}
The aim of this study was to analyze the findings on Cortical Auditory Evoked Potentials in children with cochlear implant through a systematic literature review. After formulation of research question and search of studies in four data bases with the following descriptors: electrophysiology (eletrofisiologia), cochlear implantation (implante coclear), child (criança), neuronal plasticity (plasticidade neuronal) and audiology (audiologia), were selected articles (original and complete) published between 2002 and 2013 in Brazilian Portuguese or English. A total of 208 studies were found; however, only 13 contemplated the established criteria and were further analyzed; was made data extraction for analysis of methodology and content of the studies. The results described suggest rapid changes in P1 component of Cortical Auditory Evoked Potentials in children with cochlear implants. Although there are few studies on the theme, cochlear implant has been shown to produce effective changes in central auditory path ways especially in children implanted before 3 years and 6 months of age.
\end{abstract}

\section{RESUMO}

O objetivo do presente estudo foi analisar os resultados dos Potenciais Evocados Auditivos Corticais em crianças usuárias de Implante Coclear, por meio da revisão sistemática da literatura. Após formulação da pergunta da pesquisa e levantamento dos estudos em quatro bases de dados com os descritores: eletrofisiologia (electrophysiology), implante coclear (cochlear implantation), criança (child), plasticidade neuronal (neuronal plasticity) e audiologia (audiology), foram selecionados artigos (originais e completos) publicados entre 2002 e 2013 na língua portuguesa ou inglesa. Por meio disto, foram localizados 208 estudos; contudo, apenas 13 contemplaram os critérios estabelecidos e foram lidos na íntegra; foi realizada a extração de dados para análise da metodologia e conteúdo das pesquisas. Os resultados descritos sugerem rápidas modificações no componente P1 dos Potenciais Evocados Auditivos Corticais em crianças usuárias de implante coclear. Apesar dos poucos estudos sobre o tema, o implante coclear tem se mostrado capaz de gerar modificações efetivas nas vias auditivas centrais, principalmente em crianças implantadas antes dos 3 anos e 6 meses de idade.

Study carried out at School of Medicine, Universidade de São Paulo - USP - São Paulo (SP), Brazil. (1) School of Medicine, Universidade de São Paulo - USP - São Paulo (SP), Brazil.

Financial support: São Paulo Research Foundation (FAPESP).

Conflict of interests: nothing to declare. 


\section{INTRODUCTION}

Deafness is a pathology that prevents the full reception of acoustic signals by the auditory cortex, since it reduces the number of sound waves that stimulate auditory pathways ${ }^{(1)}$. When deep, it can affect the individual's personality, relationships, and lifestyle in general ${ }^{(2)}$.

The normal maturation of central auditory pathways is a condition that precedes the normal speech and language development among children. These findings are possible thanks to the neural plasticity phenomenon ${ }^{(3)}$, which allows the brain maturation required for the development of oral language $\mathrm{e}^{(4-6)}$. The adequate auditory stimulation during childhood allows the cortex to go through changes and reorganizations, which will enable the development of the skill that discriminates sounds arriving to the central auditory system ${ }^{(7-9)}$.

With the technological and scientific advances in the past decades, the cochlear implant (CI), or bionic ear, is no longer just an instrument of scientific investigation, thus becoming an effective clinical resource that is able to improve the quality of life of adults and children with severe and/or deep bilateral sensorineural hearing impairment.

Among children with severe and/or deep bilateral hearing loss who did not present significant results for the development of hearing skills with the use of the conventional amplification, the CI can be indicated as an intervention proposal ${ }^{(10)}$.

This sophisticated electronic device aims at partially replacing the sensory function of the hearing organ by the direct stimulation of auditory nerve fibers, thus providing their users with the possibility to know or recognize the sound world ${ }^{(11)}$.

The benefits of CI, especially concerning oral language, depend on the necessary auditory stimulation for the development of speech perception within a critical period ${ }^{(12-14)}$. The deepest layers of the cortex may go through maturation processes even at the absence of stimulation, however, the most superficial ones require the stimulation of auditory pathways during a critical period, probably from the age of 3-6 years old, so that maturation can occur properly ${ }^{(15)}$. After the critical period, abnormalities in the development of synaptic plasticity are observed, resulting in the abnormal connectivity between neuronal cells, functional disintegration, and immaturity of auditory cortical areas; and, consequently, some auditory areas start performing non-auditory functions, leading to abnormalities in the restructuration of cognitive functions ${ }^{(16)}$.

Nowadays, audiology services have provided objective and subjective techniques to assess hearing and language skills by means of specific tests, which should be employed according to the age and level of development of the child. They assist both in the decision process to install the electronic device and in the adaptation of the necessary programming parameters for the effective functioning of CI.

A way to objectively measure the level of development and the limits of plasticity of the central auditory pathway is by examining changes in morphology and in values of cortical auditory-evoked potentials (CAEP), with the component $\mathrm{P} 1-\mathrm{N} 1-\mathrm{P} 2^{(13,17)}$.

The P1 wave of the CAEP was established as a biomarker to assess maturation of the central auditory system in children. Therefore, these measures can help and verify the effectiveness of auditory rehabilitation in children who wear individual sound amplification devices and/or $\mathrm{CI}^{(17)}$.

With the use of CI, the tendency is that synaptic connections become more stimulated, and that the results obtained in this procedure presents change. The gradual decrease of latencies is a result of the gradual increase in the velocity of neural transmission, related to myelination changes and to the increased synaptic synchronization ${ }^{(18,19)}$.

Considering that the development and organization of central auditory pathways in children are closely related to an effective hearing experience, the use of CAEPs as a procedure that can especially reflect the activities of cortical and thalamic regions seems to be potentially valid to determine the integrity of the auditory pathway and to monitor neurophysiological changes in the population with hearing loss after intervention and auditory stimulation by the $\mathrm{CI}^{(20)}$.

\section{OBJECTIVE}

To analyze the changes in morphology and latency values of CAEP in children wearing CI by a systematic literature review.

\section{METHODOLOGY}

The first step consisted of the elaboration of the research question for the bibliographic research: "Which are the characteristics of P1 wave morphology and/or latency of CAEPs by means of electrical stimulation via CI?".

The systematic review of scientific literature consisted of the search for studies in Portuguese and English, published in the past 10 years (from January 2002 to June 2013). The databases used were Lilacs, PubMed, Medline, Science Direct, and SciELO.

The research descriptors were: electrophysiology, cochlear implantation, child, neuronal plasticity, and audiology, with their corresponding translation in Portuguese (eletrofisiologia, implante coclear, criança, plasticidade neuronal, $e$ audiologia).

\section{Selection criteria}

Inclusion criteria were: complete articles, whose participants were children, users of CI, submitted to the CAEP examination, and those that answered the research question.

Exclusion criteria were: articles with experts' opinions, literature review, and abstracts in congress annals, letters, and comments.

\section{Data analysis}

The evaluation for the inclusion of studies was performed by two reviewers: divergences were cleared with 
discussion. Data were obtained by one author and checked by another author. At first, selection was based on the titles and abstracts. The studies were fully read and analyzed according to the used methodology and CAEP results.

Studies were analyzed as to the aspects related to the objective of the research, the used methodology, the obtained results (P1 wave morphology and latency, when specified), and the conclusion of each study.

\section{RESULTS}

\section{Results on electronic databases}

As a result of the search, 256 studies were found distributed in the databases. Among these, 34 were found in more than one database and excluded. Among the 222 selected titles, 14 could not be recovered because their electronic access was not open; in total, 208 articles were recovered. The titles and abstracts of the 208 articles were read; among these, 195 were not selected for not meeting one or more of the defined criteria and, consequently, for not answering the research question (Figure 1). A total of 13 studies on CAEP with children wearing CI were selected and fully read (Chart 1).

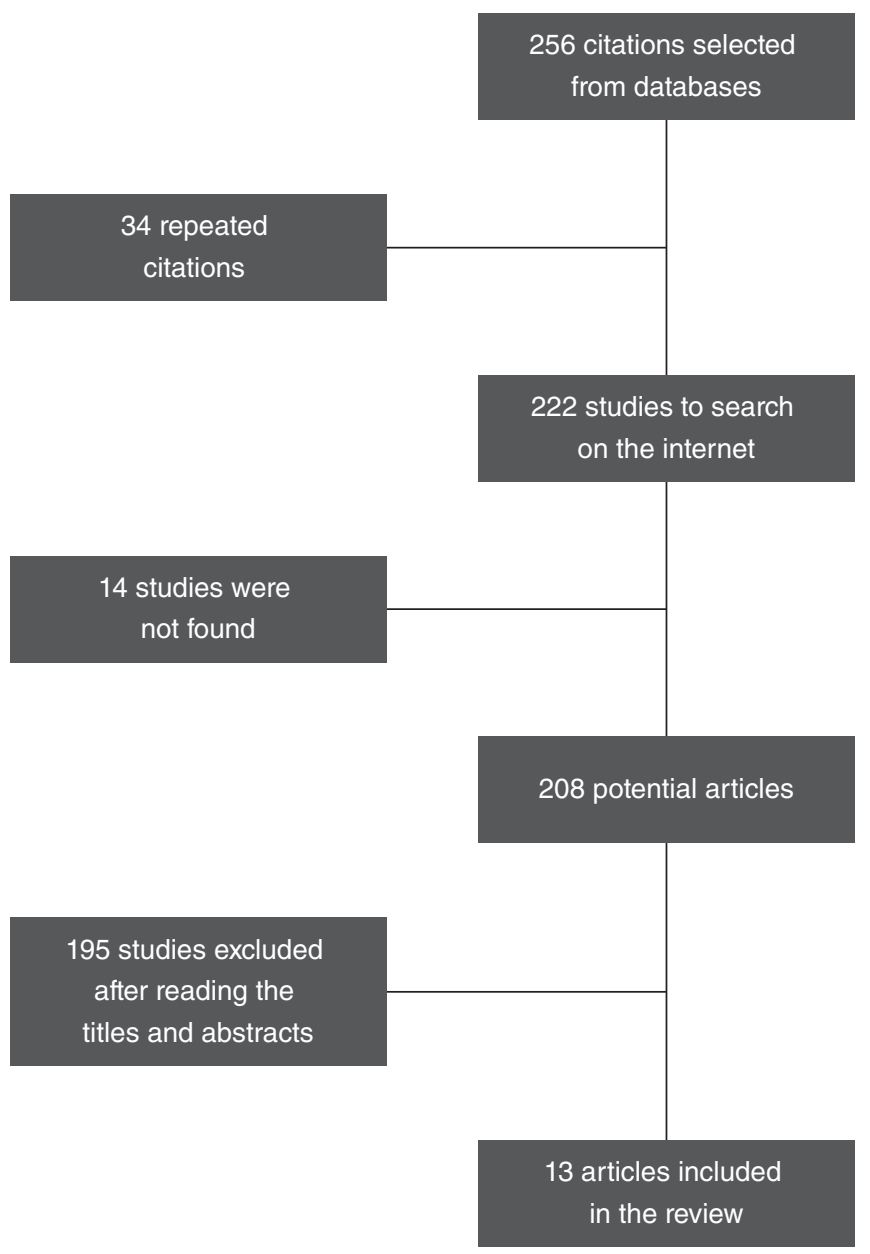

Figure 1. Synthesis of the article selection process
Chart 1. References of the articles included in the literature review

Included articles

1. Sharma A, Dorman MF, Spahr AJ. Rapid development of cortical auditory evoked potentials after early cochlear implantation. Neuroreport. 2002;13(10):1365-8.

2. Sharma A, Tobey E, Dorman M, Bharadwaj S, Martin K, Gilley $P$, et al. Central auditory maturation and babbling development in infants with cochlear implants. Arch Otolaryngol Head Neck Surg. 2004;130(5):511-6.

3. Sharma A, Dorman MF, Kral A. The influence of a sensitive period on central auditory development in children with unilateral and bilateral cochlear implants. Hear Res. 2005;203(1-2):134-43.

4. Sharma A, Martin K, Roland P, Bauer P, Sweeney MH, Gilley $P$, et al. P1 latency as a biomarker for central auditory development in children with hearing impairment. J Am Acad Audiol. 2005;16(8):564-73.

5. Bauer PW, Sharma A, Martin K, Dorman M. Central auditory development in children with bilateral cochlear implants. Arch Otolaryngol Head Neck Surg. 2006;132(10):1133-6.

6. Dorman MF, Sharma A, Gilley P, Martin K, Roland P. Central auditory development: evidence from CAEP measurements in children fit with cochlear implants. J Commun Disord. 2007;40(4):284-94.

7. Sharma A, Gilley P, Martin K, Roland P, Bauer P, Dorman M Simultaneous versus sequential bilateral implantation in young children: effects on central auditory system development and plasticity. Audiol Med. 2007;5(4):218-23.

8. Sharma A, Nash AA, Dorman M. Cortical development, plasticity and re-organization in children with cochlear implants. J Commun Disord. 2009;42(4):272-9.

9. Jang JH, Jang HK, Kim SE, Oh SH, Chang SO, Lee JH. Analysis of P1 latency in normal hearing and profound sensorineural hearing loss. Clin Exp Otorhinolaryngol. 2010;3(4):194-8.

10. Alvarenga KF, Amorim RB, Agostinho-Pesse RS, Costa OA, Nascimento LT, Bevilacqua MC. Speech perception and cortical auditory evoked potentials in cochlear implant users with auditory neuropathy spectrum disorders. Int J Pediatr Otorhinolaryngol. 2012;76(9):1332-8.

11. Thabet MT, Said NM. Cortical auditory evoked potential (P1): a potential objective indicator for auditory rehabilitation outcome. Int J Pediatr Otorhinolaryngol. 2012;76(12):1712-8.

12. Jiwani S, Papsin BC, Gordon KA. Central auditory development after long-term cochlear implant use. Clin Neurophysiol. 2013;124(9):1868-80.

13. Cardon G, Sharma A. Central auditory maturation and behavioral outcome in children with auditory neuropathy spectrum disorder who use cochlear implants. Int J Audiol. 2013;52(9):577-86. 


\section{Analysis of the selected studies}

The presence of only a few studies was observed in the literature discussing the cortical auditory potentials among CI users; however, their analyses indicate similarities.

Among the found studies, it was observed that the methodological approach comprehended studies with two cases and cross-sectional studies with the inclusion of 79 individuals, with ages ranging from 1 to 19 years old. There were five articles describing case analyses. Among these, three analyzed two cases ${ }^{(5,13,21)}$, one assessed three cases $^{(22)}$, and one analyzed four cases ${ }^{(23)}$. Eight studies assessed a larger sample: from 14 to 79 participants ${ }^{(18,20,21,24-29)}$. Among these, only three had a control group ${ }^{(18,28,29)}$.

Concerning the aspects of type of study, there were seven longitudinal analyses ${ }^{(5,21-25,29)}$ and six cross-sectional studies ${ }^{(13,18,20,26-28)}$.

Five studies combined the results of the CAEP electrophysiological tests with behavioral assessments, indicating that the decreased P1 latency is correlated with the improved communication behaviors (vocalization) ${ }^{(5)}$, improvement of speech and language skills ${ }^{(22)}$, and improvement of speech among children ${ }^{(13,26,29)}$.

Still comparing the electrophysiological and the behavioral assessments, another article analyzed P1 values with the results of rehabilitation by dividing the children wearing CI in two subgroups: with adequate rehabilitation (effective use of CI and speech language pathology and audiology therapy, with aurioral approach three times a week), and with inadequate rehabilitation (no effective use of CI and lack of regular attendance to therapy sessions). It was observed that, in the first group, latency values were lower, while the amplitude of a wave was larger in relation to the second group. The authors concluded that the CAEP evaluation can be a useful clinical tool to verify auditory rehabilitation ${ }^{(27)}$. The analysis leads to the conclusion that decreased P1 latency values among children who wear the CI reflect directly on the velocity of cortical reorganization, and that the maturation of auditory pathways result in the faster development of auditory and linguistic skills.

The results obtained by the selected studies have demonstrated, in general, that decreased P1 latency values with the use of CI, which turns the CAEP analysis into a useful tool to analyze the cortical maturation in implanted children, so it can be used as a biomarker that is able to assess the development of cortical auditory pathways and assist in the surgical conduct and in the monitoring of auditory rehabilitation ${ }^{(21,22,27)}$

Despite that, the presentation of wave latency values is not clearly reported. In most of the described studies, latency values are presented by graphs. This practice may be didactic, but it prevents the precise description of P1 latency values. Likewise, there is no specific criterion to characterize the morphology of the wave, which made the description of this aspect difficult.

Among the 13 selected studies, nine presented the P1 latency values in graphs $s^{(5,13,20-23,25,28,29)}$. Four studies described the latency values in tables. In one of them, the P1 latency in groups of children who had been implanted too early, that is, aged less than 3 years and 5 months old, presented mean values of $378 \mathrm{~ms}$ at the time of activation and $137 \mathrm{~ms}$ after 12-18 months with the CI; and, in a group of children who had been implanted later, that is, older than 7 years old, the mean P1 latency values were $245 \mathrm{~ms}$ at activation and 148 ms 12-18 months after the activation of the electrodes $^{(24)}$. In the second study, P1 latency was analyzed in three groups of individuals aged between 1 and 17 years old; a group of listeners, whose found values were 61-122 ms, decreased with aging; a group of deaf children before the activation of CI electrodes, in which latency values were observed between 110 and $198 \mathrm{~ms}$; and, finally, a group of children who already had the CI, presenting latency values between 65 and $13 \mathrm{~ms}^{(18)}$. The third study analyzed a population of children aged between 4 and 11 years old, diagnosed with auditory neuropathy, who were already wearing the CI, and P1 latency was about 97 and $134 \mathrm{~ms}$ for children with good and bad performances in speech perception tests, respectively ${ }^{(26)}$. Finally, latency values of about 94 and $129 \mathrm{~ms}$ were observed for children with adequate or inadequate rehabilitation, respectively ${ }^{(27)}$.

In the studies that described P1 latency values, it was observed that data suggested in the literature are very variable. These values in individuals aged up to 17 years old ranged from 110 to $378 \mathrm{~ms}$ before CI activation, and from 65 to $148 \mathrm{~ms}$ after a hearing experience using this device.

Concerning the aspects related to morphology, eight articles were found that described such a parameter. Five of them described the presence of negativity preceding the P1 wave observed in deaf children, which, on the other hand, demonstrates decreased latency and amplitude until completely vanishing according to the experience of $\mathrm{CI}$ use. The studies presented variable values; however, close, as to time of experience of $\mathrm{CI}$ so that the design could be adequate to the expected for the age: 3 months, 8 months, 6-8 months of stimulation in children who had been implanted too early and, among those who had been implanted later, the beginning of the decrease in latency and amplitude of this negativity took place after 12-19 months, 3-6 months, 3.5 months, and also, 6 months of CI use ${ }^{(5,20-22,25,29)}$. One other study described the presence of normal P1 and with large amplitude among children with adequate rehabilitation, unlike the scenario for children without an adequate rehabilitation, for whom the design is characterized with polyphasic waves ${ }^{(27)}$.

The last study, which also analyzes the morphology of the design, observed that the answers of CI users, even if presenting evolution with time, still remain different from the results of children who listen, even after 10 years of hearing experience with $\mathrm{CI}^{(29)}$.

Two important aspects that are very present in the analyzed literature are the decreasing P1 latency in relation to time of use and age at CI activation.

Eight studies analyzed the variable in relation to time of CI use $\mathrm{e}^{(5,18,20,22,23,25,28,29)}$. Among them, seven studies observed decreased P1 latency with increasing hearing experience. 
On the other hand, the other study ${ }^{(18)}$ observed that even though P1 latencies seemed to be late in a group of children using CI in comparison to another group of non-implanted children, this difference was not statistically significant; the authors justified this finding with the individual differences of each individual, and suggest new studies comparing the same subject in two moments: pre and post-surgery.

Concerning the age of activation, four studies reported decreased P1 with age in activation and time of CI use ${ }^{(13,21,24,29)}$. The first one compared the results of two children: one of them was implanted early, and the other one, later. For the latter, the observed result and wave latency were abnormal, with polyphasic waves, and for the first one, the component was within normality. In the second study, two groups of children were observed: those who had been implanted early and those who had been implanted later. The first group reached the expected normality values after 4 months of stimulation, and the second one maintained late P1 latency even after 13 months of stimulation via CI. The third study demonstrated that, at the time of activation, children who had been implanted early presented later P1 latencies than those implanted later; however, the latter demonstrated slower decrease in the P1 latency than the first ones, while, after 12-18 months of wearing CI, latency became similar for both groups, and morphology was not adequate for children who had been implanted late. Among these studies, it was observed that the main conclusion is the existence of a critical period, in which auditory stimulation should be initiated in order to obtain more clinical efficacy. Children who had the implants before the age of 2 years old presented normal P1 latencies, while those implanted later showed late latencies ${ }^{(29)}$.

One final aspect concerns the P1 latency in cases of bilateral implant observed in three articles. In one of them, the focus was on activation time - when CI is activated too early, there are fast changes in latency ${ }^{(21)}$. The other two analyzed the difference between the bilateral implant performed sequentially or simultaneously ${ }^{(23,25)}$. It was observed that children who received the CI sequentially presented P1 values within normality after 3-6 months of wearing the first implant, and after 1 month of wearing the second one. Those implanted simultaneously presented normality values after 1 month of stimulation; and, in both situations, individuals reached the expected values for their age after wearing the CI for 3.5 months.

In cases of bilateral CI, it was observed that there is no consensus over which conduct (sequential or simultaneous) is more effective for cortical maturation and, consequently, which one would suggest P1 latency values close to normality faster; however, it is possible to conclude that all of them defend the existence of a critical period for the efficacy of the treatment.

\section{CONCLUSION}

This review helped us to observe that there are a few studies, especially national ones, describing the changes taking place in the central auditory nervous system after the use of CI by the registration of CAEPs.

Despite that, by analyzing the found studies, a consensus was observed in the literature as to the use of CI providing changes in central auditory pathways, which can be registered by the fast decrease of P1 latency values of the CAEPs, especially when the CI activation occurs before the age of 3 years and 6 months old.

* LAFS was in charge of data collection and tabulation; MIVC followed-up collection and collaborated with data analysis; CGM and ACMC were responsible for the project and study design, as well as the general orientation of the stages of execution and elaboration of the manuscript.

\section{REFERENCES}

1. Mendes BCA. Percepção e produção da fala e deficiência auditiva. In: Bevilacqua MC, Martinez MAN, Balen AS, Pupo AC, Reis ACM, Frota S. Tratado de Audiologia. São Paulo: Santos, 2011. p. 653-69.

2. Bento RF, Brito Neto R, Castilho AM, Gómez VG, Giorgi SB, Guedes MC. Resultados auditivos com o implante coclear multicanal em pacientes submetidos a cirurgia no Hospital das Clínicas da Faculdade de Medicina da Universidade de São Paulo. Rev Bras Otorrinolaringol. 2004;70(5):632-7.

3. Boéchat EM. Plasticidade e amplificação. In: Fernandes FDM, Mendes BCA, Navas ALP (orgs.). Tratado de Fonoaudilogia. São Paulo: Roca, 2010. p. 160-8.

4. Maurer J, Collet L, Pelster H, Truy E, Gallégo S. Auditory late cortical response and speech recognition in digisonic cochlear implant users. Laryngoscope. 2002;112(12):2220-4.

5. Sharma A, Tobey E, Dorman M, Bharadwaj S, Martin K, Gilley P, et al. Central auditory maturation and babbling development in infants with cochlear implants. Arch Otolaryngol Head Neck Surg. 2004;130(5):511-6.

6. Thai-Van H, Veuillet E, Norena A, Guiraud J, Collet L. Plasticity of tonotopic maps in humans: influence of hearing loss, hearing aids and cochlear implants. Acta Otolaryngol. 2010;130(3):333-7.

7. Moret ALM, Bevilacqua MC, Costa OA. Implante coclear: audição e linguagem em crianças deficientes auditivas pré-linguais. Pró-Fono $\mathrm{R}$ Atual Cient. 2007;19(3):295-304.

8. Gilley PM, Sharma A, Dorman MF. Cortical reorganization in children with cochlear implants. Brain Res. 2008;1239:56-65.

9. Dinces E, Chobot-Rhodd J, Sussman E. Behavioral and electrophysiological measures of auditory change detection in children following late cochlear implantation: a preliminary study. Int J Pediatr Otorhinolaryngol. 2009;73(6):843-51.

10. Bevilacqua MC, Costa AO, Carvalho ACM, Moret ALM. Implante Coclear. In: Fernandes FDM, Mendes BCA, Navas ALP (orgs.). Tratado de Fonoaudilogia. São Paulo: Roca, 2010. p. 220-31.

11. Clark G. Cochlear implants: fundamentals \& applications. New York: Springer, 2003.

12. Sharma A, Dorman MF. Central auditory development in children with cochlear implants: clinical implications. Adv Otorhinolaryngol. 2006;64:66-88.

13. Sharma A, Nash AA, Dorman M. Cortical development, plasticity and re-organization in children with cochlear implants. J Commun Disord. 2009;42(4):272-9.

14. Fallon JB, Irvine DRF, Shepherd RK. Neural prostheses and brain plasticity. J Neural Eng. 2009;6(6):065008.

15. Eggermont JJ, Ponton CW. Auditory-evoked potential studies of cortical maturation in normal hearing and implanted children: correlations with changes in structure and speech perception. Acta Otolaryngol. 2003;123(2):249-52. 
16. Kral A, Sharma A. Developmental neuroplasticity after cochlear implantation. Trends Neurosci. 2012;35(2):111-22.

17. Nash A, Sharma A, Martin K, Biever A. Clinical applications of the P1 cortical auditory evoked potential (CAEP) biomarker. A sound foundation through early amplification: proceedings of a Fourth International Conference. Chicago, 2007.

18. Jang JH, Jang HK, Kim SE, Oh SH, Chang SO, Lee JH. Analysis of P1 latency in normal hearing and profound sensorineural hearing loss. Clin Exp Otorhinolaryngol. 2010;3(4):194-8.

19. Ventura LMP. Maturação do sistema auditivo em crianças ouvintes normais: potenciais evocados auditivos de longa latência [dissertação] Bauru: Faculdade de Odontologia de Bauru, Universidade de São Paulo; 2008

20. Sharma A, Dorman MF, Spahr AJ. Rapid development of cortical auditory evoked potentials after early cochlear implantation. Neuroreport. 2002;13(10):1365-8.

21. Dorman MF, Sharma A, Gilley P, Martin K, Roland P. Central auditory development: evidence from CAEP measurements in children fit with cochlear implants. J Commun Disord. 2007;40(4): 284-94.

22. Sharma A, Martin K, Roland P, Bauer P, Sweeney MH, Gilley P, et al. P1 latency as a biomarker for central auditory development in children with hearing impairment. J Am Acad Audiol. 2005;16(8):564-73.
23. Bauer PW, Sharma A, Martin K, Dorman M. Central auditory development in children with bilateral cochlear implants. Arch Otolaryngol Head Neck Surg. 2006;132(10):1133-6.

24. Sharma A, Dorman MF, Kral A. The influence of a sensitive period on central auditory development in children with unilateral and bilateral cochlear implants. Hear Res. 2005;203(1-2):134-43.

25. Sharma A, Gilley P, Martin K, Roland P, Bauer P, Dorman M. Simultaneous versus sequential bilateral implantation in young children: effects on central auditory system development and plasticity. Audiol Med. 2007;5(4):218-23.

26. Alvarenga KF, Amorim RB, Agostinho-Pesse RS, Costa OA, Nascimento LT, Bevilacqua MC. Speech perception and cortical auditory evoked potentials in cochlear implant users with auditory neuropathy spectrum disorders. Int J Pediatr Otorhinolaryngol. 2012;76(9):1332-8.

27. Thabet MT, Said NM. Cortical auditory evoked potential (P1): a potential objective indicator for auditory rehabilitation outcome. Int J Pediatr Otorhinolaryngol. 2012;76(12):1712-8.

28. Jiwani S, Papsin BC, Gordon KA. Central auditory development after long-term cochlear implant use. Clin Neurophysiol. 2013;124(9): 1868-80.

29. Cardon G, Sharma A. Central auditory maturation and behavioral outcome in children with auditory neuropathy spectrum disorder who use cochlear implants. Int J Audiol. 2013;52(9):577-86. 